\title{
Toxocara cati and other parasitic enteropathogens: more commonly found in owned cats with gastrointestinal signs than in clinically healthy ones
}

Aurora L. Ursache

University of Agricultural Sciences and Veterinary Medicine Cluj-Napoca

Adriana Györke ( $\boldsymbol{D}$ adriana.gyorke@usamvcluj.ro)

University of Agricultural Sciences and Veterinary Medicine Cluj-Napoca https://orcid.org/0000-0001-

6453-2370

Viorica Mircean

University of Agricultural Sciences and Veterinary Medicine Cluj-Napoca

Mirabela Oana Dumitrache

University of Agricultural Sciences and Veterinary Medicine Cluj-Napoca

Andrei Răzvan Codea

University of Agricultural Sciences and Veterinary Medicine Cluj-Napoca

Vasile Cozma

University of Agricultural Sciences and Veterinary Medicine Cluj-Napoca

\section{Research Article}

Keywords: T. cati, enteropathogens, parasites, gastrointestinal signs, cats, risk factors

Posted Date: January 25th, 2021

DOl: https://doi.org/10.21203/rs.3.rs-153658/v1

License: (c) (i) This work is licensed under a Creative Commons Attribution 4.0 International License.

Read Full License 


\section{Toxocara cati and other parasitic enteropathogens: more commonly found in 2 owned cats with gastrointestinal signs than in clinically healthy ones}

4 Aurora L. Ursache ${ }^{1}$, Adriana Györke ${ }^{1}$, Viorica Mircean¹, Mirabela Oana Dumitrache ${ }^{1}$, Andrei 5 Răzvan Codea ${ }^{2}$, Vasile Cozma ${ }^{1,3}$

61 -Department of Parasitology and Parasitic Diseases, University of Agricultural Sciences and Veterinary Medicine Cluj-Napoca,

7 Calea Mănăştur 3-5, Cluj-Napoca 400372, Cluj, Romania

82 -Department of Internal Medicine, University of Agricultural Sciences and Veterinary Medicine Cluj-Napoca, Calea Mănăştur

9 3-5, Cluj-Napoca 400372, Cluj, Romania

3 -Academy of Agriculture and Forestry Sciences Gheorghe Ionescu-Siseşti (A.S.A.S.), 61 Mărăşsti Boulevard, Bucharest 011464,

Romania.

Correspondence: Tel. +40264-596384, Fax+40264-593792, E-mail adriana.gyorke@usamvcluj.ro

\section{Abstract}

Gastrointestinal parasites are involved in the health and wellbeing of cats and some of them, due to their zoonotic character represent a problem for the public health. This study aimed to assess the prevalence of parasitic infections in cats with digestive symptoms. Faecal samples collected from 137 cats were analysed by the flotation method using sodium chloride saturated solution. The overall prevalence of gastrointestinal (GI) parasites was 56.6\%. GI parasites were significantly $(\mathrm{p}=0.005)$ more common in cats with digestive symptoms $(69.8 \%)$ than in clinically healthy ones (23.0\%). Toxocara cati $(40.2 \%)$ was the most frequently identified GI parasite, followed by Cystoisospora spp. (10.2\%), Ancylostoma tubaeforme (3.7\%), Taenia spp. (2.2), Giardia duodenalis $(2.2 \%)$, and Toxoplasma gondii-like oocysts $(0.7 \%)$. T. cati $(53.3 \%, p<0.0001)$ and Cystoisospora spp. $(15.6 \%, \mathrm{p}<0.001)$ were significantly more frequently diagnosed in cats with digestive symptoms. Lack of deworming in the last three months (OR: 15.9), outdoor access (OR: 13.8), the presence of digestive symptoms (OR: 5.4), and young age (OR: 4.2) were identified as risk factors for $T$. cati infection by logistic regression analysis. Regardless of the age, symptoms like vomiting, diarrhoea, and inappetence were positively associated with T. cati.

Keywords: $T$. cati, enteropathogens, parasites, gastrointestinal signs, cats, risk factors. 
In the last years, the number of cats increased considerably in the urban areas worldwide. It is considered that the proven benefits of companion animals to the mental, emotional, and physical health of humans [1] might play an important role in this dynamic. By the year 2019, in Europe, approximately 106.4 million cats were estimated to be raised as pets and Romania is one of the countries with a considerable interest for feline companionship, with $47 \%$ of the households owning at least one cat [2,3]. Gastrointestinal disorders are a common concern of the owner when bringing the cat to the veterinary clinics for a health check-up [4,5]. The identification of the underlaying cause can be a challenge for clinicians, but it is desirable for an efficient and complete therapeutic protocol and management. Among dietary and stress-related problems or intestinal primary disorders, various pathogens such as viruses, bacteria, and parasites can be responsible for the development of gastrointestinal (GI) signs in companion animals [6,7]. Parasitic enteropathogens, both protozoa and helminths, are numerous and one of the causes for gastrointestinal disturbances expressed by diarrhoea, vomiting and/or changes in appetite [8,9], therefore faecal testing must be taken into consideration for differential diagnosis whenever digestive clinical signs are present [10]. Moreover, it is necessary to protect human-animal interaction by limiting the exposure to various infectious agents that can represent a risk to both cats and humans such as Toxocara cati, hookworms, Giardia duodenalis, Toxoplasma gondii, Dipilidium caninum and Echinoccocus multilocularis [11,12].

52 Toxocara cati is a nematode frequently found in the intestine of domestic cats worldwide, with differences in prevalence based on geographical areas, laboratory methods used for diagnostics and structure of the tested feline population [13].

55 Cats can get infected by oral route with $T$. cati infective eggs from the environment, through lactogenic transmission of larvae from the queen to the kittens or by consumption of paratenic hosts, such as mice or birds, that contain somatic larvae [14]. Patent infections contribute to the environmental contamination through faeces, as hundreds of thousands of Toxocara spp. unembryonated eggs per animal are released daily [15]. Besides the veterinary importance, $T$. cati represents a threat to public health, being able to cause human toxocariasis, a severe condition which has four major forms of development: visceral toxocariasis, neurotoxocariasis, ocular toxocariasis, and covert toxocariasis [16]. T. cati is less 
incriminated than T. canis, but its zoonotic potential should not be underestimated [17]. Humans can contaminate by ingesting embryonated eggs from the environment and consumption of unwashed fruits or vegetables and by ingesting infective larvae through consumption of raw meat [18,19]. T. cati may be an important soil-transmitted helminth especially in children. This can be due to the increased number of free-ranging cats and their behaviour of defecating near playgrounds, sandpits, and different urban outdoor public areas [20].

It is necessary to continuously assess the prevalence of zoonotic gastrointestinal parasites such as T. cati in domestic cats along with the parasitic contamination of the environment, to have a realistic picture regarding the risk for animal and public health. Also, epidemiological studies regarding correlations between clinical signs and involvement of enteropathogens such as $T$. cati are desirable in providing a better understanding of medical aspects among feline populations for veterinarians. In this frame, this study aimed to evaluate the prevalence of $T$. cati and other parasitic enteropathogens in cats with GI signs, but also to identify the risk factors associated with the parasitic infection.

\section{Results}

The age of the cats from this study was between 4 weeks and 15 years with an average of 26.03 $( \pm 3.68)$ months; $66(48.2 \%)$ cats were under 6 months old (2.96 \pm 0.19 months), $39(28.5 \%)$ were between 6 months and 2 years old (14.64 \pm 1.18 months), and $32(23.4 \%)$ individuals were over 2 years old (77.23 \pm 8.19 months). The ratio between males and females was 1.05. Most of the cats were mixed breed (128/137). Ninety-six (70.1\%) out of 137 cats had outdoor access, and only 74 $(54.0 \%)$ cats were dewormed in the last three months. More than half $(65.7 \%)$ of cats referred to our laboratory presented one or more digestive signs as vomiting $(n=21)$, diarrhoea $(n=78)$, or inappetence $(n=31)$. Digestive signs were more common in outdoor cats $(78.8 \%)$, kittens $(63.3 \%)$, and in un-dewormed cats $(53.3 \%)$.

Seventy-two (52.6\%) out of 137 examined faecal samples from owned cats referred to our laboratory were positive for at least one GI parasite; they were significantly more common in cats with digestive symptoms $(n=61 ; 67.8 \%)$ than in clinically healthy ones $(n=11 ; 23.0 \%)(\mathrm{p}<0.005)$. T. cati $(40.2 \%)$ was significantly $\left(x^{2}=131.14, p<0.00001\right)$ the most frequently found GI parasite, followed by Cystoisospora spp. (10.2\%), Aelurostrongylus abstrusus (4.4\%), Ancylostoma 
94 tubaeforme (3.7\%), Giardia duodenalis (2.2\%), Taenia spp. (2.2\%), Toxoplasma gondii-like 95 (0.7\%), and Capillaria aerophila (0.7\%). Cystoisospora spp., G. duodenalis, and T. gondii-like 96 were exclusively, and $T$. cati was predominantly identified in cats with digestive symptoms. 97 Overall, and in cats with digestive signs single infection was significantly $(p<0.00001)$ more 98 prevalent than mixed infection (Table 1). Nevertheless, 14 out of 17 mixed infections were 99 registered in symptomatic cats, and in 12 out of 17 mixed infections was involved T. cati. T. cati 100 and Cystoiospora spp. was the most commonly found co-infection (5.8\%) and the only one 101 significantly involved in cats with digestive symptoms $(8.9 \%, \mathrm{p}<0.05)$. This association was 102 registered only in outdoor cats and mainly in kittens (7/8) (unshown data). Lungworms $A$. 103 abstrusus and C. aerophila in cats with digestive symptoms were identified in co-infection with 104 T. cati (unshown data).

105 Forty-eight (53.3\%) out of 90 cats with digestive symptoms were infected with $T$. cati, and the 106 prevalence was significantly higher $(p<0.00001)$ in symptomatic cats comparing with healthy ones 107 (14.9\%) (Table 1). According to the age category, 57.9\% of kittens with digestive signs were 108 infected with T. cati, $50.0 \%$ of young cats, and $36.4 \%$ of adult cats (Table 2). However, there was 109 a decreasing trend of $T$. cati in symptomatic cats with age this was not statistically significant $110\left[x^{2}(2,90)=1.85, p=0.40\right]$. Indoor and dewormed cats with digestive signs were less commonly 111 infected with $T$. cati and the prevalence was not significantly different from those without clinical 112 signs (Table 2). 
114 Table 1. Frequency, prevalence $[n(\%)]$, and 95\% confidence interval of GI parasites identified in owned cats with or without digestive 115 symptoms

\begin{tabular}{|c|c|c|c|c|c|c|c|}
\hline \multirow[t]{2}{*}{ Parasite } & \multicolumn{2}{|l|}{ Total $(n=137)$} & \multicolumn{2}{|c|}{$\begin{array}{l}\text { Cats with digestive symptoms } \\
(n=90)\end{array}$} & \multicolumn{2}{|c|}{$\begin{array}{l}\text { Clinically healthy cats } \\
(n=47)\end{array}$} & \multirow[t]{2}{*}{$P$} \\
\hline & $n(\%)$ & $95 \% \mathrm{CI}$ & $n(\%)$ & $95 \% \mathrm{CI}$ & $n(\%)$ & $95 \% \mathrm{CI}$ & \\
\hline T. cati & $55(40.2)^{* * *}$ & $31.9-48.9$ & $48(53.3)$ & $42.5-64.0$ & $7(14.9)$ & $6.2-28.3$ & 0.0000 \\
\hline Cystoisospora spp. & $14(10.2)$ & $5.7-16.6$ & $14(15.6)$ & $8.8-24.7$ & 0 & - & 0.0009 \\
\hline G. duodenalis & $3(2.2)$ & $0.5-6.3$ & $3(3.3)$ & $0.7-9.4$ & 0 & - & 0.1401 \\
\hline A. tubaeforme & $5(3.7)$ & \begin{tabular}{|l}
$1.2-8.3$ \\
\end{tabular} & $4(4.4)$ & $1.2-11.0$ & $1(2.1)$ & $0.1-11.3$ & 0.2783 \\
\hline Taenia spp. & $3(2.2)$ & $0.5-16.6$ & $1(1.1)$ & $0.0-6.0$ & $2(4.3)$ & $0.5-14.5$ & 0.1547 \\
\hline T. gondii-like & $1(0.7)$ & $0.0-4.0$ & $1(1.1)$ & $0.0-6.0$ & 0 & - & 0.3284 \\
\hline A. abstrusus & $6(4.4)$ & $1.6-9.3$ & $2(2.2)$ & $0.3-7.8$ & $4(8.5)$ & $2.4-20.9$ & 0.0615 \\
\hline C. aerophila & $1(0.7)$ & $0.0-4.0$ & $1(1.1)$ & $0.0-6.0$ & 0 & - & 0.3284 \\
\hline Single infection & $55(40.1)$ & $31.9-48.9$ & $47(52.2)$ & $41.4-62.9$ & $8(17.0)$ & $7.7-30.8$ & 0.0000 \\
\hline Mixed infection & $17(12.4)$ & $7.4-19.1$ & $14(15.6)$ & $8.8-24.7$ & $3(6.4)$ & $1.3-17.5$ & 0.0635 \\
\hline Total & $72(52.6)$ & $43.9-61.1$ & $61(67.8)$ & $57.1-77.3$ & $11(23.0)$ & $12.3-38.0$ & 0.0000 \\
\hline
\end{tabular}


118 Table 2. Prevalence of $T$. cati by each variable in cats with and without digestive symptoms (diarrhea, vomiting, and inappetence)

\begin{tabular}{|c|c|c|c|c|c|c|c|}
\hline & \multicolumn{2}{|l|}{ Total $(n=137)$} & \multicolumn{2}{|c|}{$\begin{array}{l}\text { Cats with digestive symptoms } \\
(n=90)\end{array}$} & \multicolumn{2}{|c|}{$\begin{array}{l}\text { Clinically healthy cats } \\
(n=47)\end{array}$} & \multirow[t]{2}{*}{$P$} \\
\hline & $n(\%)$ & $95 \% \mathrm{CI}$ & $n(\%)$ & $95 \% \mathrm{CI}$ & $n(\%)$ & $95 \% \mathrm{CI}$ & \\
\hline \multicolumn{8}{|l|}{ Age } \\
\hline$<6$ months & $34(51.5)^{* *}$ & $38.9-64.0$ & $33(57.9)$ & $44.1-70.9$ & $1(11.1)$ & $0.3-48.3$ & 0.006 \\
\hline 6months-2years & $15(38.5)$ & $23.4-55.4$ & $11(50.0)$ & $28.2-71.8$ & $4(23.5)$ & $6.8-49.9$ & 0.05 \\
\hline$>2$ years & $6(18.8)$ & $7.2-36.4$ & $4(36.4)$ & $10.9-69.2$ & $2(9.5)$ & $1.2-30.4$ & 0.05 \\
\hline \multicolumn{8}{|l|}{ Gender } \\
\hline Females & $30(47.8)$ & $32.6-57.4$ & $26(65.0)$ & $48.3-79.4$ & $4(14.8)$ & $4.2-33.7$ & 0.0000 \\
\hline Males & $25(35.7)$ & $24.6-48.1$ & $22(44.0)$ & $30.0-58.8$ & $3(15.0)$ & $3.2-37.9$ & 0.01 \\
\hline \multicolumn{8}{|l|}{ Outdoor access } \\
\hline Yes & $53(55.2) * * *$ & $44.7-65.4$ & $46(64.8)$ & $52.5-75.8$ & $7(28.0)$ & $12.1-49.4$ & 0.0009 \\
\hline No & $2(4.9)$ & $0.6-16.5$ & $2(10.5)$ & $1.3-33.1$ & 0 & - & 0.10 \\
\hline \multicolumn{8}{|c|}{ Dewormed in the last 3 months } \\
\hline Yes & $10(13.5)$ & $6.7-23.5$ & $8(19.1)$ & $8.6-34.1$ & $2(6.3)$ & $0.8-20.8$ & 0.06 \\
\hline No & $45(71.4)^{* * *}$ & $58.7-82.1$ & $40(83.3)$ & $69.8-95.5$ & $5(33.3)$ & $11.8-61.6$ & 0.0002 \\
\hline
\end{tabular}


120 In kittens and young cats, diarrhoea (47/48) was significantly $\left[x^{2}(2,144)=55.03, p<0.00001\right]$ the 121 most frequent digestive symptom in cats infected with $T$. cati as unique (24/48) symptom or in 122 combination (23/48) with other digestive symptoms [vomiting (12/48), and inappetence (22/48)] 123 (Figure 1).

124

125

126

127

128

129

130

131

132

133

134

135

136

137

138

139

140

32

33

34

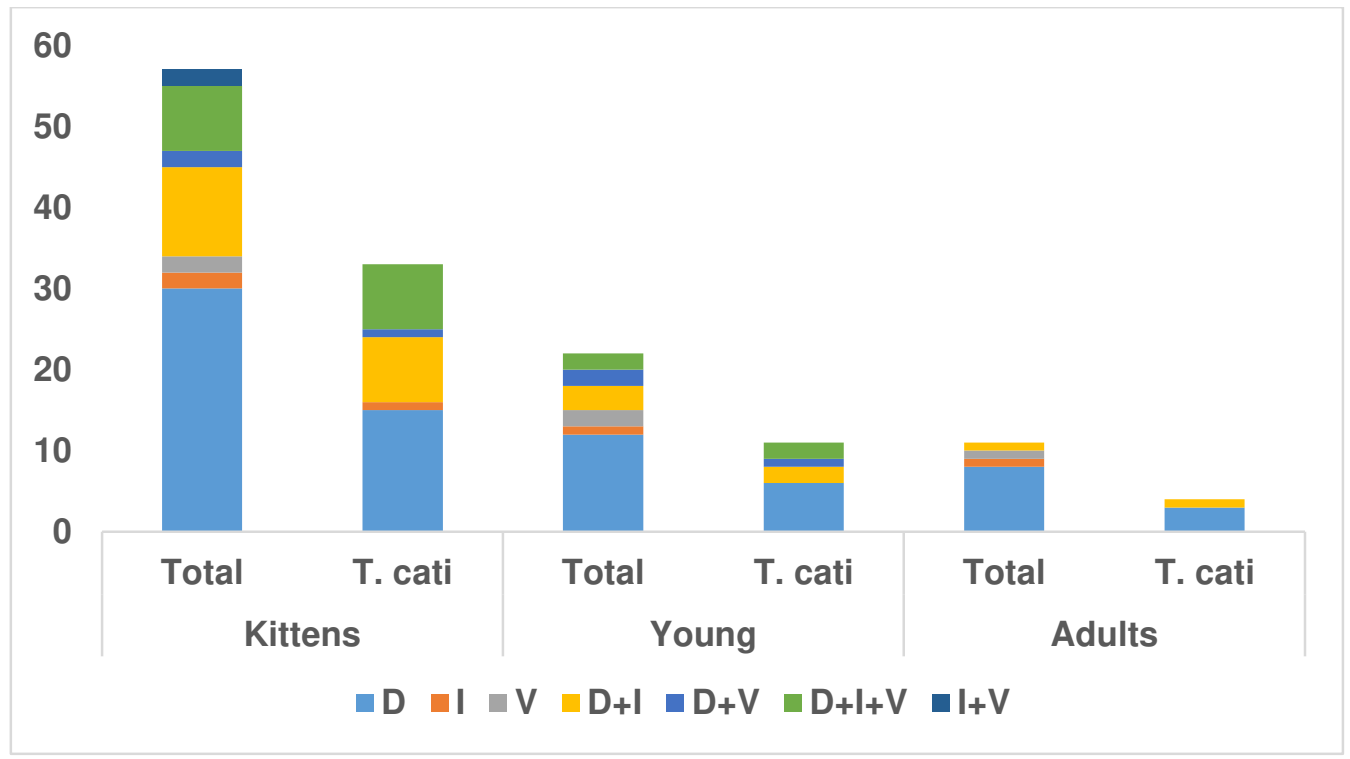

Figure 1. Digestive clinical signs identified in owned cats infected with T. cati by age group (D

- diarrhea; I - innapetence; V - vomiting)

Lack of deworming in the last three months (OR: 15.9), outdoor access (OR: 13.8), the presence of digestive symptoms (OR: 5.4), and young age (OR: 4.2) were identified as risk factors for $T$. cati infection in owned cats by logistic regression analysis (Table 3 ).

35

36


141 Table 3. Risk factors for $T$. cati infection in domestic owned cats

\begin{tabular}{|c|c|c|c|}
\hline & OR & $95 \% \mathrm{CI}$ & $p$ \\
\hline \multicolumn{4}{|l|}{ Age } \\
\hline $0-24$ months old & 4.2 & $1.03-17.15$ & 0.05 \\
\hline$>24$ months old & Ref. & & \\
\hline \multicolumn{4}{|l|}{ Gender } \\
\hline Males & 0.55 & $0.20-1.52$ & 0.25 \\
\hline Females & Ref. & & \\
\hline \multicolumn{4}{|l|}{ Outdoor access } \\
\hline Yes & 13.82 & $2.45-78.04$ & 0.003 \\
\hline No & Ref. & & \\
\hline \multicolumn{4}{|c|}{ Dewormed in the last 3 months } \\
\hline No & 15.85 & $5.43-46.24$ & 0.00001 \\
\hline Yes & Ref. & & \\
\hline \multicolumn{4}{|c|}{ Digestive symptoms } \\
\hline No & Ref. & & \\
\hline Yes & 5.37 & $1.60-18.01$ & 0.006 \\
\hline
\end{tabular}

142

143

144

145

146

147

148

149

150

151

152

153

154

155

156

157

158

159

\section{Discussions}

Gastrointestinal parasites are often diagnosed in companion animals; they affect the health and wellbeing of dogs and cats, and some of them are also of public health interest. Therefore, epidemiological studies are important in continuously updating data regarding prevalence and associated risk factors for parasitic diseases. Regardless of the presence or absence of digestive symptoms, the overall prevalence of GI parasites in owned cats from this study was high (52.6\%), and four zoonotic parasites were identified (Giardia spp., Toxoplasma-like, T. cati, and hookworms). T. cati was the most prevalent GI parasite (40.2\%), and significantly more prevalent in symptomatic (53.3\%), than in asymptomatic owned cats (14.9\%). Different studies have been identified T. cati as the most frequently found parasite in domestic cats [13,24]. In Europe, $T$. cati prevalence varies between $7.2 \%$ and $83.3 \%$ with an average prevalence of $17.8 \%$ [11,24-26]. The prevalence of $T$. cati in household/owned and asymptomatic cats in Romania lies in the reported average for Europe according to this study and a previous one (20.3\%) [27]. However, the prevalence of T.cati positive cats may differ depending on geographical regions, rural or urban areas, and exposure to risk factors. In western European countries are reported lower prevalences comparing with southern, central, and eastern European countries [24,25]. 
Numerous studies aimed to establish the correlation between exposure to different risk factors and infection with $T$. cati in cats. In the current study, outdoor access and lack of deworming were identified as the main risk factors, but also the age and presence of digestive clinical signs.

Cats with outdoor access were 13.82 times more susceptible of being $T$. cati positive than indoor cats. This emphasizes the possibility of free-roaming and predatory behaviour significantly increasing the risk for infection also for cats with owners. This risk factor was assessed also by other authors $[24,27,28]$ and a positive correlation was observed between the time a cat spends outdoor and the probability of a T. cati patent infection to occur [13]. Cats without an anthelmintic treatment in the last three months before sample collection were 15.9 more likely to be infected with $T$. cati. Prevalence of patent infection decreases if the frequency of anthelmintic treatment per year increases as shown in the study of Beugnet et al. [24]. Other studies did not find a positive association between patent T. cati infection and the time past from the last deworming of the cats, but suggest further investigations in this direction [13]. The European Scientific Council Companion Animal Parasites (ESCCAP) recommends a deworming frequency of four times a year and faecal examinations, but also a prevention and control management that can be adapted to individuals depending on exposure to risk factors. Kittens should start receiving deworming treatment every two weeks starting at three weeks of age until two weeks after weaning and monthly until they are six months. Moreover, for adult cats exposed to the infection through paratenic hosts from free roaming and outside access, a monthly treatment is recommended [29]. Cats of all ages are prone to patent infections with $T$. cati, therefore have the potential to be sources of contamination [30]. Nevertheless, in the current study, young age (0-2 years) represented a risk factor, with an increased rate of infection in kittens $(51.5 \%)$. This is similar with the results obtain in other studies [13,27,31]. However, cats over 2 years should not be neglected as a potential reservoir for $T$. cati as the prevalence was still high (18.8\%) probably due to the predatory behaviour of outdoor cats (40\%) [30]. T. cati larvae that harbor in different tissues or organs of the paratenic hosts, such as small mammals or birds [32] once ingested by the definitive host, they develop and reach adult stages in the small intestines [17]. Gender was not found to be a risk factor and the same results were obtained by others $[11,33]$.

Multiparasitism has significant relevance for the course of the disease, and also gives information about which antiparasitic medication should be chosen according to the cat's age and risks of 
exposure. T. cati was found in 16 out of 17 cases of mixed infections, and the most prevalent mixed infection was between $T$. cati and Cystoisospora spp in outdoor kittens.

Clinical signs are one of the main reasons of owners concerns and therefore for a vet consult. Few studies were made on correlations between gastrointestinal symptoms and various pathogens in feline populations. Their results are of both epidemiological and clinical importance since they can give the proper tools for veterinarians in establishing the most appropriate diagnostic and therapeutic protocols based on risk factors and clinical aspects of each individual. In this study, the involvement of parasites, especially of $T$. cati in cats with or without digestive symptoms was assessed. Parasitic pathogens were involved in a high percentage of cats with digestive symptoms (67.8\%). Increased prevalence of parasites in cats with gastrointestinal symptoms was also found by others [34]. More than half of the cats $(53.3 \%)$ that were brought with gastrointestinal signs were positive for $T$. cati infection. Contrary, in other studies Giardia spp. was more frequently found in cats with diarrheic faeces [6,34]. However, a higher prevalence of T. cati (5-30\%) was found in unowned cats with diarrhoea coming from different settlements [35]. In this study, the presence of digestive symptoms and associated risk factors for feline toxocarosis (young age, outdoor access, lack of deworming) strongly suggests the infection with $T$. cati in cats. It was observed that regardless of the age of cats, diarrhoea can be significantly linked to T. cati patent infection. Besides the clinical and therapeutic implications that this correlation has, it can be assumed that zoonotic potential may be increased in cats with diarrhoea. A high prevalence of toxocarosis was seen also in cats with inappetence, therefore, this symptom can also be suggestive for $T$. cati. Furthermore, the involvement of the parasite increased with the number of associated digestive symptoms. Although age can be a risk factor, the implication of $T$. cati as a pathogen involved in digestive symptoms was not influenced by the cat's age. That emphasizes that the parasite should not be excluded from the list of differential diagnoses in gastrointestinal disturbances even for older cats.

An overall high percentage of parasitic pathogens were found in cats, but more importantly, in ones with digestive symptoms. Some of the identified parasites represent a concern in both animal and human health. Identifying correlations between patent infections with $T$. cati, clinical manifestations and various associated factors in cats is of real interest for establishing the proper diagnosis and developing efficient measures for treatment and control for feline infection, environmental contamination, and most importantly the zoonotic risk that this parasitic disease represents. 
221 The results of this study confirm the high rate of infection with $T$. cati and involvement of other

222 parasitic enteropathogens in the aetiology of gastrointestinal symptoms in cats. Faecal testing is

223 highly recommended as a routine examination in clinically healthy animals and as an important

224 diagnostic tool in individuals with digestive signs, that could also reduce environment and human

225 contamination.

226

227 Material and methods

228 Animals, samples, questionnaires, and samples analysis

229 Over a three year period, 137 cats that were presented at the Emergency and Critical Care 230 Department of the Veterinary Medicine Faculty were tested microscopically for intestinal parasites 231 at the Parasitology and Parasitic Diseases Department (University of Agricultural Sciences and 232 Veterinary Medicine Cluj-Napoca - Faculty of Veterinary Medicine) for differential diagnosis or 233 a periodical health check-up. Approximately 3-5 grams of faeces per sample were analysed using 234 a flotation method in hypersaturated sodium chloride solution (sp. gr. 1.20) and examined after 30 235 minutes under a light microscope at a magnification of x10, x20, and x40 when necessary. 236 Identification of parasitic elements (cysts, oocysts, eggs) was based on morphological 237 characteristics [21,22].

238 Each cat owner received a questionnaire to fill in identification data for cats. The information was 239 later used to assess possible risk factors that can influence the distribution of parasites:age, breed, 240 and gender, the reason of presentation, digestive clinical signs, living condition (indoor, outdoor), 241 and deworming status in the last three months.

243 Statistical analysis

244 Frequency, prevalence, and its 95\% confidence interval were calculated for total infection, each 245 parasite, co-infection, and studied variables. The variables were represented by age, gender, living 246 condition, presence or absence of digestive signs, and deworming status. According to the age, cats 247 were divided into three groups as follows: 0-6 months old (kittens), between 6 months and 2 years 248 old (young cats), and over 2 years old (adult cats). Chi-square test was used to establish the 249 differences in prevalence among studied variables. Risk factors associated with feline infection with 250 T. cati were analysed by binary and multinomial logistic regression analysis. Statistical significance 
251 was established for a $p$-value equal to or less than 0.05. The statistical analysis was done with Epi

252 Info $^{\text {TM }} 7$ software (CDC, USA) [23].

253

254 Author Contributions: ALU conceptualization, data curation, formal analysis, investigation, 255 methodology, writing - original draft \& editing; AG data curation, statistical analysis, supervision,

256 validation, visualization, writing - review \& editing; VM data curation, validation; MOD writing

257 - review \& editing; ARC clinical examination, data and sample collection; VC supervision, 258 validation.

259

260

Funding:

261

262

263

264

265

266

Institutional Review Board Statement: Not applicable.

Informed Consent Statement: Not applicable.

267

268

Acknowledgments: Not applicable.

269

270

Conflicts of Interest: The authors declare no conflict of interest.

271

272

273

274

275

276

277

278

279

280 


\section{References}

1. Barker, S.B.; Wolen, A.R. The benefits of human-companion animal interaction: A review. J. Med. Vet. Educ. 2008, 35, 487-496, doi:10.3138/jvme.35.4.487.

2. https://www.statista.com/statistics/516041/cat-population-europe-europe/ (accessed on October 28, 2020)

3. https://www.statista.com/statistics/515464/cat-ownership-european-union-eu-by-country/ (accessed on 28 October, 2020)

4. Lund, E.M.; Armstrong, P.J.; Kirk, C.A.; Kolar, L.M.; Klausnor, J.S. Health status and population characteristics of dogs and cats examined at private veterinary practices in the

5. Jones, P.H.; Dawson, S.; Gaskell, R.M.; Coyne, K.P.; Tierney, A.;, Setzkorn, C.; Radford, A.D; Noble PJ. Surveillance of diarrhoea in small animal practice through the Small Animal Veterinary Surveillance Network (SAVSNET). Vet. J. 2014, 201, 412-418, doi: 10.1016/j.tvj1.2014.05.044.

6. Sabshin, S.J.; Levy, J.K.; Tupler, T.; Tucker, S.J.; Greiner, E.C; Leutenegger, C.M. Enteropathogens identified in cats entering a Florida animal shelter with normal feces or diarrhea. J. Am. Vet. Med. Assoc. 2012, 241, 331-337, doi: 10.2460/javma.241.3.331.

7. Tello, L.; Perez-Freytes, R. Fluid and electrolyte therapy during vomiting and diarrhea. Vet. Clin. North. Am. Small Anim. Pract. 2017, 47, 505-519, doi: 10.1016/j.cvsm.2016.09.013.

8. Deplazes, P.; Eckert, J.; Mathis, A.; Samson-Himmelstjerna, G.V.; Zahner, H. 2016. Parasitology in veterinary medicine; Wageningen Academic Publishers: Wageningen, The Netherlands, 2016, ISBN: 978-90-8686-247-0

9. Marks, S.L. Chapter 11- Diarrhea. In Canine and Feline Gastroenterology; Washabau, R.J; Day, M.J., Eds.; W.B. Saunders 2013; pp. 99-108, ISBN 9781416036616, https://doi.org/10.1016/B978-1-4160-3661-6.00011-0

10. Matz, M.E; Guilford, W.G.; Laboratory procedures for the diagnosis of gastrointestinal tract diseases of dogs and cats. N. Z. Vet. J. 2003, 51, 292-301, doi: 10.1080/00480169.2003.36383. 
11. Symeonidou, I.; Gelasakis, A.I.; Arsenopoulos, K.; Angelou, A.; Beugnet, F.; Papadopoulos, E. Feline gastrointestinal parasitism in Greece: emergent zoonotic species and associated risk factors. Parasit. Vectors. 2018, 11, 227, doi: 10.1186/s13071-0182812-x.

12. Robertson, I.D; Thompson, R.C. Enteric parasitic zoonoses of domesticated dogs and cats. Microbes. Infect. 2002, 48, 867-873, doi: 10.1016/s1286-4579(02)01607-6

13. Nijsse, R.; Ploeger, H.W.; Wagenaar, J.A.; Mughini-Gras, L. Prevalence and risk factors for patent Toxocara infections in cats and cat owners' attitude towards deworming. Parasitol. Res. 2016, 115, 4519-4525, doi: 10.1007/s00436-016-5242-8

14. Overgaauw, P.A; Nederland, V. Aspects of Toxocara epidemiology: toxocarosis in dogs and cats. Crit. Rev. Microbiol. 1997, 23, pp.233-251, doi: 10.3109/10408419709115138

15. Glickman, L.T; Schantz, P.M. Epidemiology and pathogenesis of zoonotic toxocariasis. Epidemiol. Rev. 1981 3, 230-250, 10.1093/oxfordjournals.epirev.a036235.

16. Macpherson, C.N. The epidemiology and public health importance of toxocariasis: a zoonosis of global importance. Int. J. Parasitol. 2013, 43, 999-1008, doi: 10.1016/j.ijpara.2013.07.004.

17. Fisher, M. (2003). Toxocara cati: an underestimated zoonotic agent. Trends Parasitol. 2003, 19, 167-170, doi: 10.1016/s1471-4922(03)00027-8.

18. Glickman, L. T.; Shofer, F.S. Zoonotic visceral and ocular larva migrans. Vet. Clin. North. Am. Small Anim. Pract. 1987, 17, 39-53, doi: 10.1016/s0195-5616(87)50604-0.

19. Taira, K.; Saeed, I.; Permin, A.; Kapel, C.M.O. Zoonotic risk of Toxocara canis infection through consumption of pig or poultry viscera. Vet. Parasitol. 2004, 121, 115-124, doi: 10.1016/j.vetpar.2004.01.018.

20. Gerhold, R.W.; Jessup, D.A. Zoonotic diseases associated with free-roaming cats. Zoonoses. Public. Health. 2013, 60, 189-195, doi: 10.1111/j.1863-2378.2012.01522.x.

21. Mircean, V.; Cozma, V.; Gyorke, A. Coproscopical diagnostic of parasitic diseases in animals, [In Romanian]; Risoprint: Cluj-Napoca, Romania, 2011, ISBN: 978-973-530542-0

22. Taylor, M.A.; Coop, R.L; Wall, R.L. Veterinary parasitology, 3rd ed.; Blackwell Publishing: Oxford, UK, ISBN: 978-1-118-68711-6 
23. Dean, A.G.; Arner, T.G.; Sunki, G.G.; Friedman, R.; Lantinga, M.; Sangam, S.; ... \& Fagan, R.F. (). Epi Info ${ }^{\mathrm{TM}}$, a database and statistics program for public health professionals. $C D C$, Atlanta, GA, USA. 2011

24. Beugnet, F.; Bourdeau, P.; Chalvet-Monfray, K.; Cozma, V.; Farkas, R.; Guillot, J.; Halos, L.; Joachim, A.; Losson, B.; Miró, G.; Otranto, D.; Renaud, M.; Rinaldi, L. Parasites of domestic owned cats in Europe: co-infestations and risk factors. Parasit. Vectors. 2014, 7, 291, doi: 10.1186/1756-3305-7-291.

25. Giannelli, A.; Capelli, G.; Joachim, A.; Hinney, B.; Losson, B.; Kirkova, Z.; RenéMartellet, M.; Papadopoulos, E.; Farkas, R.; Napoli, E.; et al. Lungworms and gastrointestinal parasites of domestic cats: a European perspective. Int. J. Parasitol. 2017, 47, 517-528, doi: 10.1016/j.ijpara.2017.02.003.

26. Rostami, A.; Sepidarkish, M.; Ma, G.; Wang, T.; Ebrahimi, M.; Fakhri, Y.; Mirjalali, H.; Hofmann, A.; Macpherson, C.N.; Hotez, P.J.; Gasser, R.B. Global prevalence of Toxocara infection in cats. Adv. Parasitol. 2020, 109, 615, doi: 10.1016/bs.apar.2020.01.025.

27. Mircean, V.; Titilincu, A.; Vasile, C. Prevalence of endoparasites in household cat (Felis catus) populations from Transylvania (Romania) and association with risk factors. Vet. Parasitol. 2010, 171, 163-166, doi: 10.1016/j.vetpar.2010.03.005.

28. Näreaho, A.; Puomio, J.; Saarinen, K.; Jokelainen, P.; Juselius, T.; Sukura, A. Feline intestinal parasites in Finland: prevalence, risk factors and anthelmintic treatment practices. J. Feline. Med. Surg. 2012, 14, 378-383, doi: 10.1177/1098612X12439257.

29. ESCCAP Worm Control in Dogs and Cats ESCCAP Guideline 01 Sixth Edition - February 2020. Available online: https://www.esccap.org/guidelines/gl1/ (accessed on 18 January 2021

30. Overgaauw, P. A.; van Knapen, F. Veterinary and public health aspects of Toxocara spp. Vet. Parasitol. 2013, 193, 398-403, doi: 10.1016/j.vetpar.2012.12.035.

31. Barutzki, D.; Schaper, R. Endoparasites in dogs and cats in Germany 1999-2002. Parasitol. Res. 2003, 90, S148-S150, doi: 10.1007/s00436-003-0922-6.

32. Strube, C.; Heuer, L.; Janecek, E. 2013. Toxocara spp. infections in paratenic hosts. Vet. Parasitol. 2013, 193, 375-389, doi: 10.1016/j.vetpar.2012.12.033.

33. Zanzani, S.A.; Gazzonis, A.L.; Scarpa, P.; Berrilli, F.; Manfredi, M.T. Intestinal parasites of owned dogs and cats from metropolitan and micropolitan areas: prevalence, zoonotic 
risks, and pet owner awareness in northern Italy. BioMed Res. Int. 2014, 2014, 1-10, 10.1155/2014/696508.

34. López-Arias, Á.; Villar, D.; López-Osorio, S.; Calle-Vélez, D.; Chaparro-Gutiérrez, J.J. Giardia is the most prevalent parasitic infection in dogs and cats with diarrhea in the city of Medellín, Colombia. Vet. Parasitol. Reg. Stud. Reports 2019, 18, 100335, doi: 10.1016/j.vprsr.2019.100335.

35. Andersen, L.A.; Levy, J.K.; McManus, C.M.; McGorray, S.P.; Leutenegger, C.M., Piccione, J.; Blackwelder, L.K. Tucker, S.J. Prevalence of enteropathogens in cats with and without diarrhea in four different management models for unowned cats in the southeast United States. Vet. J. 2018, 236, 49-55, doi: 10.1016/j.tvj1.2018.04.008. 


\section{Figures}

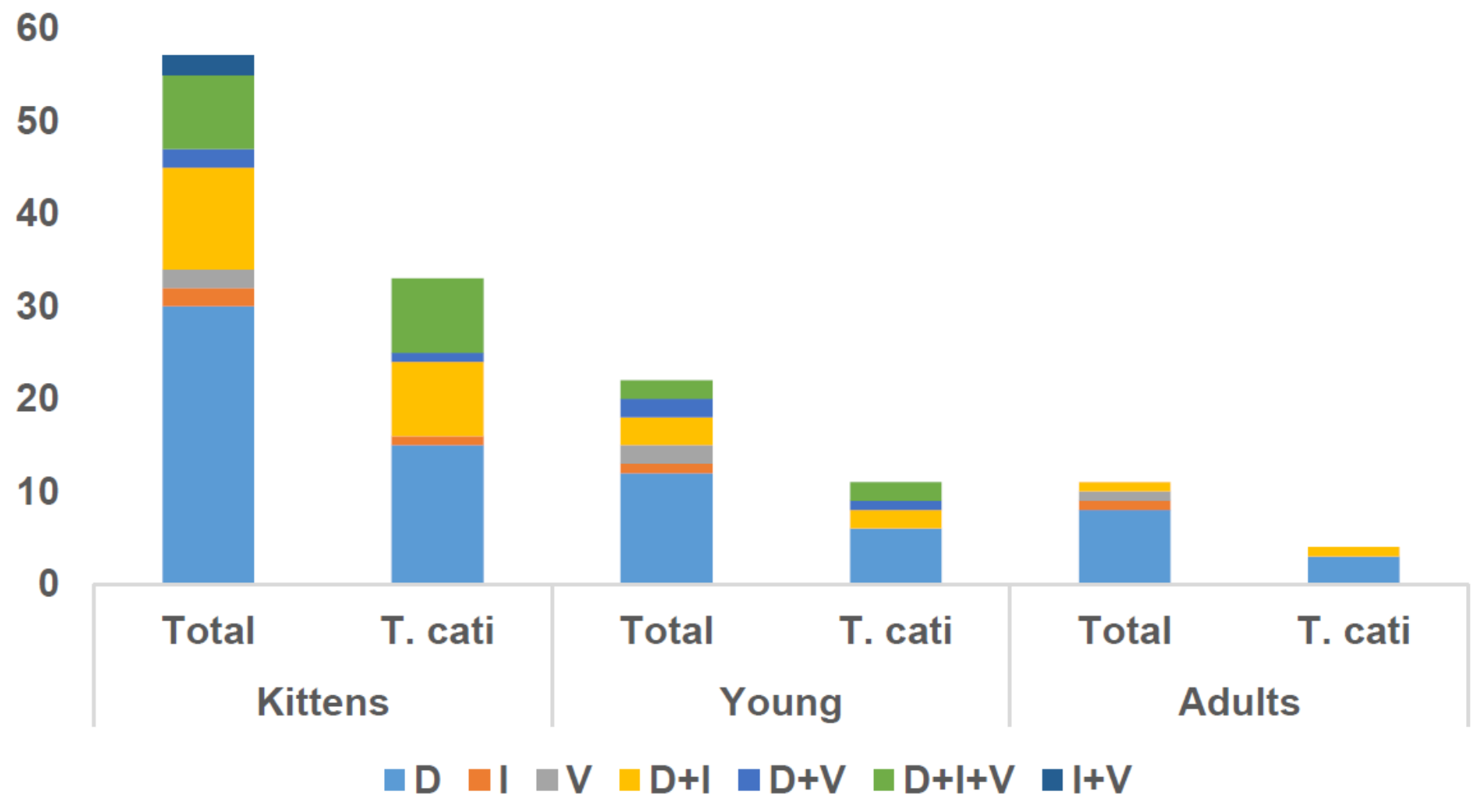

Figure 1

Digestive clinical signs identified in owned cats infected with T. cati by age group (D - diarrhea; I innapetence; $\mathrm{V}$ - vomiting) 